\title{
The Correlation between Rs1800795 Variant of $I L-6$ and Sports Performance among Turkish Elite Athletes
}

\author{
Abdullah Cenikli ${ }^{1}$, AyseFeyda Nursal ${ }^{2}$, Ercan Tural ${ }^{3}$, Yahya Polat ${ }^{4}$, Mehmet Yalcin \\ Tasmektepligil $^{5}$, Serbulent Yigit $^{6}$ \\ ${ }^{1}$ Gaziosmanpasa University, School of Physical Education and Sports, Department of Couching, \\ Tokat, Turkey \\ ${ }^{2}$ Hitit University, Faculty of Medicine, Department of Medical Genetics, Corum Turkey \\ ${ }^{3}$ Ondokuz Mayis University, Havza Vocational School, Therapy and Rehabilitation Department \\ Physiotherapy Programme Samsun \\ ${ }^{4}$ Erciyes University, School of Physical Education and Sports, Department of Couching, Kayseri, \\ Turkey \\ ${ }^{5}$ Ondokuz Mayis University, Yasar Dogu Faculty of Sport Sciences, Samsun, Turkey \\ ${ }^{6}$ Gaziosmanpasa University, Faculty of Medicine, Department of Medical Biology, Tokat, Turkey
}

\begin{abstract}
:
Background: It has been reported that plasma levels of interleukin-6 (IL-6) increase during physical exercise and are involved in mediating endurance capacity. We compared allelic and genotypic frequencies of the IL-6 gene G174C variant (rs1800795) among elite athletes and non-athletic control subject.
\end{abstract}

Materials Methods: The study included 92 elite Turkish athletes and 100 non-athletes. Genomic DNA isolated and genotyped using polymerase chain reaction based-restriction fragment length polymorphism (PCR-RFLP) analysis for the IL-6 gene G174C variant.

Results: In this study, the allele distribution of IL-6 gene G174C variant exhibited statistically significant difference between the elite athletes and the controls $(p=0.005)$. The $G$ allele was more prevalent among the elite athletes than the control subjects. The genotype frequencies in the studied population were as follows: GG, GC, and CC in the controls were 40\%, 45\% and 15\%, and in the elite athletes were 50\%, 43.5\%, and 6.5\%, respectively. However, there was not any statistically significant difference in the genotype frequencies of the IL-6 G174C variant between the elite athletes and the control groups ( $p>0.05)$.

Conclusion: Our study suggests that a strong association exists between the IL-6 G174C variant and elite endurance performance in the Turkish population. Further studies in populations of different ethnic background are necessary to prove the association of IL-6 variant with sports performance.

Keywords: Interleukin-6 gene, G174C variant, elite athletes, sportperformance.

\section{INTRODUCTION}

Physical performance is important for athletic activities. The musculoskeletal system and the central nervous system have been implicated to play a significant role in physical performance. Alteration in neurotransmitter levels, such as serotonin, and cytokines have been observed during the initial phases of fatigue(Davis, Bailey 1997).Giving recombinant human interleukin-6 (rhIL-6) to an individual enhances the feeling of fatigue both during exercise(Robson-Ansley PJ 2004)and rest(Späth-Schwalbe E 1998)supporting this hypothesis. Current studies suggest that this protein has a crucial role in muscle repair and hypertrophy after exercise-induced damage (Ruiz 2010).

IL-6, a multifunctional pro-inflammatory and immunomodulatory cytokine, could define the individual variations in health and exercise-related phenotypes. It is secreted by monocytes, endothelial cells and fibroblasts and regulates immune response, the acute phase response and, inflammation. The human $I L-6$ gene is mapped to chromosome $7 \mathrm{p} 21$ and consists of 5 exons and 4 introns (Karakus 2014). A functional G/C variant at position -174 (rs 1800795) of the IL-6 described firstly by Fischman et al. in the 5'flanking region of gene (Fishman 1998). This variability seems to be 
functional, since it regulates transcriptional process and cytokine levels, and modulates inflammatory phenotype (Li 2015).It was demonstrated that $\mathrm{G}$ allele is associated with increased transcriptional response in vitro(Ruiz 2010). It was shown that the $I L-6$ G174C variant is associated with numerous diseases and disease-related phenotype traits including non-small cell lung cancer (Bhat 2015), increased arterial stiffness (Sie 2008)polycystic ovary syndrome (Vural 2010) development of micro vascular complications in diabetic patients (Rudofsky 2009) and febrile seizures in children (Azab 2016). Also, it was reported that $I L-6$ increases significantly in the circulation during exercise (Febbraio 2003). Therefore, we compared allelic and genotypic frequencies of the $I L-6$ gene G174C variant (rs1800795) among elite athletes and non-athletic control subjects.

\section{MATERIAL AND MethodS}

\subsection{Subjects}

The study group consisted of 92 elite athletes [35 males and 25 females; mean age $\pm 23.68 \pm 12.16$ standard deviation (SD) years] and 100 (52 males and 48 females; mean age $24.9 \pm 6.7$ SD years) unrelated controls. Elite athletes were composed of subjects who played in an active team group for at least 2 years. Control group consisted of subjects who do not have any chronic disease and who do not perform any active sports. Informed written consent was obtained from each participant. The study was performed according to the Declaration of Helsinki and was approved by the local Clinical Research Ethical Committee.

\subsection{Genotype Analysis}

Total 192 subjects between the age group of 13-32 years were included in the present study. $2 \mathrm{ml}$ of venous blood obtained from each subjects. Genomic DNA was extracted from whole blood samples using a commercial DNA isolation kit (SigmaAldrich, Taufkirchen, Germany). TheIL-6 G174Cvariant was analyzed as previously described by Tseng et al. (2002) using forward (f) 5'- TTG TCA AGA CAT GCC AAA GTG CGG-3' and reverse (r) 5'- GTG CAA TGT GAC GTC CCT TAG CAT-3' primers. The amplification conditions consisted of an initialmelting step of $5 \mathrm{~min}$ at 94 C;followed by 40 cycles of $30 \mathrm{~s}$ at $94 \mathrm{C}, 30 \mathrm{~s}$ at $56 \mathrm{C}$ and 1 minat $72 \mathrm{C}$. Thenthe PCR products were digested with FastDigestBsrL-I restriction endonuclease (Fermentas) at $37^{\circ} \mathrm{C}$ for 30 minandanalyzed on a 3\% agarose gel stainedwithethidiumbromide. Twofragments (139 and $17 \mathrm{bp}$ ) for $\mathrm{G}$ all ele and three fragments $(117,22$ and $17 \mathrm{bp}$ ) for $\mathrm{C}$ all ele were determined. Second PCR was performed to confirm samples whose results were unclear.

\subsection{Statistical Analysis}

All statistical analyses were performed using computer SPSS Statistical Program Version 20.0 and Openepi 3.01 software package program. Continuous data were given as mean \pm SD (standart deviation) and (minmax). $\mathrm{Chi}^{2}$ test was used to significance of differences in the allele frequency and genotypedistribution between the two study groups. Hardy-Weinberg equilibrium test was performed for both study groups. Oddsratio (OR) and 95\% confidence intervals (CIs) were calculated. $p$ valuep $<0,05$ was considered statistically significant.

\section{RESUlts}

Table 1 summarizes the distribution of physical characteristics in athletes and control groups. The elite athletes comprised 92 athletes (age ranging between 13 and 30). The control group included 100 non-athletes (age ranging between 18 and 30).

Demographic variables and base line characteristics of elite athletes are presented Table 2.

Allelic and genotypic distributions of $I L-6$ G174C variant in elite athletes and controls are given in Table 3. The genotype frequencies in the studied population were as follows: GG, GC, and CC in the controls were $40 \%, 45 \%$ and $15 \%$, and in the elite athletes group were $50 \%, 43.5 \%$, and $6.5 \%$, respectively. There was not any statistically significant difference in the genotype frequencies of the IL-6 G174C variant between elite athletes and control groups $(p>0.05)$.

The $I L-6$ gene $\mathrm{G}$ allele was present in $71.1 \%$ of the elite athletes and $62.5 \%$ of the control group, while $\mathrm{C}$ allele frequency was $28.3 \%$ in the elite athletes and $37.5 \%$ in the control group. In this study, the allele distribution of $I L-6$ gene G174C variant showed statistically significant difference between the elite athletes and the controls $(p=0.005)$. The $\mathrm{G}$ allele was more prevalent among the elite athletes than the control subjects. 


\section{DISCUSSION}

Physical performance is a complex condition. It is influenced by several variables including genetic, environmental and lifestyle factors. Numerous genes have been reported to have crucial role in athletic performance. Cytokines make up a large group of polypeptides or proteins, which play a unifying and modulator role as universal intercellular messengers. Several studies analyzed alterations in the circulating levels of cytokines after exercise. It has been shown that $I L-6$ acts as pro- and antiinflammatory factor in response to numerous physiological activities such as exercise(Fischer 2006).

Factors involved in $I L-6$ release at the time of exercise have been studied widely. Early research on the $I L-6$ kinetics showed that arduous and prolonged physical activity elevated the levels of serum $I L$ 6 and other cytokines (Northoff 1991) leading to deterioration of the immune system(Fischer 2006). Factors that influence the plasma levels of $I L-6$ include magnitude, duration, and the muscle mass involved in endurance exercise (Ostrowski 1998).Efflux of $I L-6$ into blood can increase up to 100 -fold during an arduous exercise (18).(Pedersen 2003).During ultra-endurance activities (150 km races, triathlons and marathons) plasma $I L-6$ levels increase 50-fold or more from baseline and this correlate to several immunity factors(Wallberg 2011).

$I L-6$ is expressed in numerous tissues, such as adipose, skeletal muscle and hypothalamus, which all take a part in the regulation of body energy balance. In $I L-6$ null mice, the deficiency of plasma $I L-6$ was associated with obesity and low energy expenditure (Wallenius 2002).Some investigators also reported that $I L-6$ acts as a hormone, and that is why it exerts biological actions during heavy physical activity. This hypothesis suggests that active muscle cells secrete $I L-6$, which in turn acts as a hormonal signal to liver or adipose tissue to activate glycogenolysis or lipolysis (Steensberg 2000).

Single nucleotid polymorphisms (SNPs) in the promoter region may change the function of genes and this could explain the individual responses to physical training (Macarthur 2005). The promoter of the $I L-6$ gene is actively regulated at several sites, such as the multiple response element (-173 to 145) which acts by responding to interleukin-1(IL-1), tumor necrosis factor- $\alpha$ (TNF- $\alpha)$, and other factors (Fishman 1998). Besides, the G to C change in position -174 of the $I L-6$ gene leads to a potential site for the transcriptional factor $N F-1$, that can potentially repress the gene expression (Ruiz 2010).

G174C variation of $I L-6$, located in the gene promoter regions, can affect mRNA expression and protein levels. Alleles associated with decreased amount of $I L-6$ expression can play a role in the low cytokine secretion during physical exertion, which can lead to low level of metabolism, decreased fat burning, and eventually, obesity. Individuals with G174C genotype have two fold $I L-6$ plasma levels compared to as those who carry the homozygous CC allele (Białecka 2015). The impact of $I L-6$ G174C variant on energy consumption may indicate the role of $I L-6$ in obesity and type 2 diabetes. It was shown that the subjects bearing $\mathrm{CC}$ genotype are more resistant to insulin and have higher serum glucose concentration (Kubaszek 2003).

It was found that the $I L-6 \mathrm{G} 174 \mathrm{C}$ variant is related to high-density lipoprotein cholesterol levels (Halverstadt 2005) glucose tolerance (McKenzie 2004) and bone mass remodeling (Dhamrait 2003)in response to physical exercise. Ortlepp et al. reported a correlation between the $\mathrm{C}$ allele and maximal work capacity in Caucasian smokers (2003). Yamin et al. found a strong association between the C allele of the $I L-6$ G174C variant and skeletal muscle damage after strenuous elbow flexion exercise in young adults (2008). Ruiz et al. showed that the elite power athletes, for whom muscle hypertrophy and strength is a essential phenotype trait, are more likely to have over expression of GG genotype and $G$ allele, compared with elite endurance athletes and non-athletic control subjects (2010).

The majority of published data in sports genetics are obtained from studies performed among the European and North-American Caucasian populations. This study is the first to evaluate the IL-6 G174C variant among the elite athletes in Turkish population. The earlier study suggesting that the C allele is underrepresented in Spanish power athletes (Ruiz 2010) is consistent with the previous finding reported by Yamin et al (2008), who implied a strong and dose-dependent correlation between the $\mathrm{C}$ allele/CC genotype and increased muscle damage in response to unusually strenuous exercise in non-athletes. In our study, there were both $\mathrm{G}$ and $\mathrm{C}$ allele in elite athletes Eider et al. and Ruiz et al. reported that the $I L-6$ G174C variant GG genotype and G allele were significantly higher in the Polish power-oriented athletes and Caucasian (Spanish) descent, respectively (2013;2010). We also found that the $\mathrm{G}$ allele frequency between elite athletes and non-athletes controls was statistically different. 
In this study, the $I L-6$ G174C variant G allele was more prevalent among the elite athletes than the control subjects in Turkish population. However, there are studies reporting no association between the $\mathrm{G}$ allele of the $I L-6$ G174C variant and power sports performance in the Israeli (Caucasian) population (Eynon 2011), and South African ironman triathlon (de Milander 2009). We believe that this difference of genotype and allele frequency may depend on ethnic background.

\section{CONClusion}

There is increasing evidence suggesting that athletic ability is at least partially determined by an athlete's genetic composition. As a result, our data suggest a positive correlation between the $I L-6 \mathrm{G}$ allele and Turkish elite athletes endurance, however this finding should be confirmed by further studies conducted in groups with different ethnic origins.

\section{REFERENCES}

Azab SF, Abdalhady MA, Ali A et al (2016) Interleukin-6 gene polymorphisms in Egyptian children with febrile seizures: a case-control study. Ital J Pediatr 42: 31.

Bhat IA, Qasim I, Masoodi KZ et al (2015) Significant impact of IL-6 -174G/C but inverse relation with $-634 \mathrm{C} / \mathrm{G}$ polymorphism in patients with non-small cell lung cancer in Kashmiri population. Immunol Invest 44(4): 349-60.

Białecka M, Ostasz R, Kurzawski M et al (2015) IL6 -174G>C polymorphism is associatedwith an increased risk of psoriasis but not responsetotreatment. ExpDermatol24(2):146-7.

Davis JM, Bailey SP (1997) Possible mechanisms of central nervous system fatigue during exercise. Med Sci Sports Exerc 29(1): 45-57.

de Milander L, Stein DJ, Collins M (2009) The interleukin-6, serotonin transporter, and monoamine oxidase A genes and endurance performance during the South African Ironman Triathlon. Appl Physiol Nutr Metab 34(5):858-65.

Dhamrait SS, James L, Brull DJ et al (2003) Cortical bone resorption during exercise is interleukin-6 genotype-dependent. Eur J Appl Physiol 89(1):21-5.

Eider J, Cieszczyk P, Leońska-Duniec A et al (2013) Association of the 174 G/C polymorphism of the IL6 gene in Polish power-orientated athletes. J Sports Med Phys Fitness 53(1):88-92.

Eynon N, Ruiz JR, Meckel Y et al (2011) Is the -174 C/G polymorphism of the IL6 gene associated with elite power performance? A replication study with two different Caucasian cohorts. Exp Physiol 96(2):156-62.

Febbraio MA, Steensberg A, Keller C et al (2003) Glucose ingestion attenuates interleukin-6 release from contracting skeletal muscle in humans. J Physiol 549(Pt 2):607-12.

Fischer CP (2006) Interleukin-6 in acute exercise and training: what is the biological relevance? Exerc Immunol Rev 12:6-33.

Fishman D, Faulds G, Jeffery R et al (1998) The effect of novel polymorphisms in the interleukin-6 (IL-6) gene on IL-6 transcription and plasma IL-6 levels, and an association with systemic-onset juvenile chronic arthritis. J Clin Invest 102:1369-76.

Halverstadt A, Phares DA, Roth S et al (2005) Interleukin-6 genotype is associated with high-density lipoprotein cholesterol responses to exercise training. Biochim Biophys Acta 1734(2):143-51.

Karakus N, Yigit S, Rustemoglu A et al (2014) Effects of interleukin (IL)-6 gene polymorphisms on recurrent aphthous stomatitis. Arch Dermatol Res 306(2):173-80.

Kubaszek A, Pihlajamaki J, Komarovski V et al (2003) Promoterpolymorphisms of the TNF-alpha (G-308A) and IL-6 (C-174G) genespredicttheconversionfromimpairedglucosetolerancetotype 2 diabetes: TheFinnishDiabetesPreventionStudy. Diabetes52:1872-6.

Li F, Xie X, Li S et al (2015) Interleukin-6 gene -174G/C polymorphism and bronchial asthma risk: a meta-analysis. Int J Clin Exp Med 8(8):12601-8.

Macarthur D, North K (2005) Genes and human elite athletic performance. Human Genetics 116: 331-339.

McKenzie JA, Weiss EP, Ghiu IA et al (2004) Influence of the interleukin-6 -174 G/C gene polymorphism on exercise training-induced changes in glucose tolerance indexes. J Appl Physiol 97(4):1338-42. 
The Correlation between Rs1800795 Variant of IL-6 and Sports Performance among Turkish Elite Athletes

Northoff H, Berg A (1991) Immunologic mediators as parameters of he reaction to strenuous exercise. Int J Sports Med 1:9-15.

Ortlepp JR, Metrikat J, Vesper K et al (2003) The interleukin-6 promoter polymorphism is associated with elevated leukocyte, lymphocyte, and monocyte counts and reduced physical fitness in young healthy smokers. J Mol Med (Berl) 81(9):578-84.

Ostrowski K, Hermann C, Bangash A et al (1998) A trauma-like elevation of plasma cytokines in humans in response to treadmill running. J Physiol 513 ( Pt 3):889-94.

Pedersen BK, Steensberg A, Fischer C et al (2003) Searching for the exercise factor: is IL-6 a candidate? J Muscle Res Cell Motil 24(2-3):113-9.

Robson-Ansley PJ, de Milander L, Collins M et al (2004) Acute interleukin-6 administration impairs athletic performance in healthy, trained male runners. Can J Appl Physiol 29(4): 411-8.

Rudofsky G, Jr Schlotterer A, Reismann P et al (2009) The -174G>C IL-6 gene promoter polymorphism and diabetic microvascular complications. Horm Metab Res 41(4):308-13.

Ruiz JR, Buxens A, Artieda M et al (2010) The -174 G/C polymorphism of the IL6 gene is associated with elite power performance. J Sci Med Sport 13(5):549-53.

Sie MP, Mattace-Raso FU, Uitterlinden AG et al (2008) The interleukin-6-174 G/C promoter polymorphism and arterial stiffness; the Rotterdam Study. Vasc Health Risk Manag 4(4): 863-9.

Späth-Schwalbe E, Hansen K, Schmidt F et al (1998)Acute effects of recombinant human interleukin6 on endocrine and central nervous sleep functions in healthy men. J Clin Endocrinol Metab 83(5): 1573-9.

Steensberg A, van Hall G, Osada T et al (2000) Production of IL-6 in contracting human skeletal muscles can account for the exercise-induced increase in plasma IL-6. J Physiol 529:237-42.

Tseng LH, Chen PJ, Lin MT et al (2002) Simultaneous genotyping of single nucleotide polymorphisms in the IL-6, IL-10, TNFalpha and TNFbeta genes. Tissue Antigens 59(4): 280-6.

Vural P, Değirmencioğlu S, Saral NY et al (2010) Tumor necrosis factor alpha (-308), interleukin-6 ($174)$ and interleukin-10 (-1082) gene polymorphisms in polycystic ovary syndrome. Eur J Obstet Gynecol Reprod Biol 150(1): 61-5.

Wallberg L, Mikael Mattsson C, Enqvist JK et al (2011) Plasma IL-6 concentration during ultraendurance exercise. Eur J Appl Physiol 111(6):1081-8.

Wallenius V, Wallenius K, Ahren B et al (2002) Interleukin-6-deficient mice develop mature-onset obesity. Nat Med 8:75-79.

Yamin C, Duarte JA, Oliveira JM et al (2008) IL6 (-174) and TNFA (-308) promoter polymorphisms are associated with systemic creatine kinase response to eccentric exercise. Eur J Appl Physiol 104(3):579-86. 